\section{Effects of Temperature on Development and Survival of the Egg Parasitoid Telenomus triptus NixoN (Hymenoptera: Scelionidae) in Two Pentatomid Hosts ${ }^{1}$}

\section{Ivone M. ICUMA ${ }^{2}$ and Yoshimi HIRose}

\author{
Institute of Biological Control, Faculty of Agriculture, Kyushu \\ University, Fukuoka 812-81, Japan
}

(Received 7 July 1995)

(Accepted 7 November 1995)

Key words: Telenomus triptus, development, temperature, Piezodorus hybneri, Eysarcoris guttiger

Telenomus triptus NIxON is a major egg parasitoid of the pentatomid Piezodorus hybneri (GMelin) (TAKasu and Hirose, 1985, who referred to T. triptus as Telenomus sp.; HigUCHI, 1993), which is a serious pest of soybean in Japan (KOBAYASHI, 1972; HiRASHIMA, 1977). Eggs of another pentatomid Eysarcoris guttiger (THUNBERG) were also parasitized by T. triptus in soybean fields in Japan (TAKASU and HiROSE, 1985; HIROSE et al., unpublished). Knowledge of the effect of temperature on the development and survival of this parasitoid on the two pentatomids is essential for predicting its reproductive success through the estimation of the number of parasitoid generations per year on both hosts. For these reasons, we examined the influence of the temperature on the development and survival of $T$. triptus reared on $P$. hybneri and $E$. guttiger eggs.

The effects of the following five temperatures on the rates of development and survival of $T$. triptus were determined: $20^{\circ} \mathrm{C}, 22.5^{\circ} \mathrm{C}, 25^{\circ} \mathrm{C}, 27.5^{\circ} \mathrm{C}$ and $30^{\circ} \mathrm{C}$. All treatments were maintained in a bioclimatic chamber at $\mathrm{L}: \mathrm{D} 16: 8 \mathrm{~h}$ photoperiod.

Eggs from laboratory colonies of $P$. hybneri and $E$. guttiger were used as hosts. The laboratory host colonies of $P$. hybneri and $E$. guttiger were established from field-collected adults in Kushira town (Kagoshima Pref.) and Fukuoka city in mid August 1989 and mid July 1992, respectively. Host egg masses laid on jute strings 12 to $36 \mathrm{~h}$ before parasitization were divided into experimental masses of 20 eggs each. Twenty host egg masses of each host species were used at each temperature.

Parasitoids used in the experiments were reared on $P$. hybneri eggs. A preliminary experiment did not show that the parasitoid rearing has any effect on parasitism of E. guttiger. Initial stocks of $T$. triptus were obtained from parasitized $P$. hybneri egg masses which were collected at the same sites and time as the host culture stock. Each host egg mass was exposed to an individual mated female parasitoid (2-day-old) for 3 $h$. The parasitized host egg masses were each maintained in a glass tube $(1.8 \times 10.5 \mathrm{~cm})$ plugged with cotton in a bioclimatic chamber at each temperature until parasitoid emergence. During the periods of parasitoid emergence, host egg masses were observed twice daily. The emergence date and the number and sex of emerged parasitoids for each host egg mass were recorded. Survival rate of the parasitoid progeny for each temperature was calculated by dividing the number of emerged parasitoids by the total number of parasitoids which developed to mature larvae but failed to emerge (inside host eggs). Host eggs from which parasitoids did not emerge were dissected to determine if they developed to mature larvae, but it was impossible to determine the possible death of parasitoid progeny at younger stages.

The duration of developmental time of male and female T. triptus at different temperatures on P. hybneri and $E$. guttiger eggs is given in Table 1. Male parasitoids emerged earlier than female parasitoids at all the temperatures in both host species. Developmental time from egg to adult emergence of parasitoids of each sex was significantly shorter in $P$. hybneri eggs than in E. guttiger eggs at all the temperatures.

The regression equations describing the relationship between temperature and rate of development for T. triptus in both host species, its estimated developmental thresholds $(t)$ and thermal constants $(K)$ are presented in Table 2. Determination of thermal requirements of this parasitoid is important in estimating the possible number of generations in a year. $T$. triptus is active during the three month period, between mid July and early October in soybean fields in Fukuoka city (TAKasu and Hirose, 1985; Higughi, 1993; Hirose et al., unpublished). Degree-day accumulations were determined from the meteorological data recorded in Fukuoka city from mid July to early October during 1983-1992. The mean cumulative

\footnotetext{
' Appl. Entomol. Zool. 31 (1): 168-170 (1996)

${ }^{2}$ Present address: SHIS QI 13, conjunto 01 casa 07 Lago Sul, Brasilia DF CEP 71.600, Brazil
} 
Table 1. Developmental times from egg to adult emergence of $T$. triptus reared on eggs of $P$. hybneri and E. guttiger at various constant temperatures

\begin{tabular}{|c|c|c|c|c|}
\hline \multirow{3}{*}{ Temperature $\left({ }^{\circ} \mathrm{C}\right)$} & \multicolumn{4}{|c|}{ Mean developmental time (days) } \\
\hline & \multicolumn{2}{|c|}{ P. hybneri } & \multicolumn{2}{|c|}{ E. guttiger } \\
\hline & Male & Female & Male & Female \\
\hline 20.0 & $19.3 \mathrm{a}$ & $20.9 \mathrm{c}$ & $21.1 \mathrm{~b}$ & $22.9 \mathrm{~d}$ \\
\hline 22.5 & $15.1 \mathrm{a}$ & $15.8 \mathrm{c}$ & $16.7 \mathrm{~b}$ & $17.3 \mathrm{~d}$ \\
\hline 25.0 & $11.0 \mathrm{a}$ & $11.8 \mathrm{c}$ & $12.6 \mathrm{~b}$ & $13.1 \mathrm{~d}$ \\
\hline 27.5 & $9.5 \mathrm{a}$ & $10.2 \mathrm{c}$ & $10.7 \mathrm{~b}$ & $11.1 \mathrm{~d}$ \\
\hline 30.0 & $8.5 \mathrm{a}$ & $9.0 \mathrm{c}$ & $9.8 \mathrm{~b}$ & $10.6 \mathrm{~d}$ \\
\hline
\end{tabular}

a The figures were based on 20 males and 20 females for each host species at each temperature. To obtain these males and females, 1 male and 1 female were randomly sampled from parasitoid progeny of each of the 20 tested females. Means followed by different letters significantly $(p<0.05)$ differed between the two host species for the same parasitoid sex at each temperature by $t$-test.

Table 2. Developmental thresholds $(t)$ and thermal constants $(K)$ from egg to adult emergence of $T$. triptus reared on eggs of $P$. hybneri and $E$. guttiger

\begin{tabular}{cccccc}
\hline Host & Parasitoid sex & Regression equation & $r^{2}$ & $t\left({ }^{\circ} \mathrm{C}\right)$ & $K$ (degree-days) \\
\hline \multirow{2}{*}{ P. hybneri } & Male & $Y=0.0071 X-0.0910$ & 0.991 & 13.0 & 138.6 \\
& Female & $Y=0.0064 X-0.0800$ & 0.990 & 12.5 & 154.5 \\
E. guttiger & Male & $Y=0.0057 X-0.0666$ & 0.984 & 11.7 & 174.6 \\
& Female & $Y=0.0052 X-0.0596$ & 0.966 & 11.5 & 187.1 \\
\hline
\end{tabular}

a All slopes of the regression equations of developmental rate $(Y)$ to rearing temperature $(X)$ are significant $(p<0.01)$.

degree-days calculated for $T$. triptus females when reared in $P$. hybneri and E. guttiger were 1239.8 and 1331.8 , respectively. Thus, it follows that this parasitoid may produce 8.0 and 7.1 generations annually when developed in $P$. hybneri and E. guttiger, respectively.

The period that host eggs are available to parasitism by $T$. triptus in soybean fields is limited, varying according to host species; ca. 30 days for $P$. hybneri (Higuchi, 1993; Hirose et al., unpublished) and ca. 50 days for $E$. guttiger (Hirose et al., unpublished). Thus, the number of $T$. triptus generations produced during this period is estimated to be 3.0 in $P$. hybneri and 4.4 in $E$. guttiger. This suggests that peak reproductive activity of this parasitoid in soybean is probably attained during the relatively short period of host availability.

There was no difference in host effects on parasitoid survival at any temperature (Table 3). Survival of T. triptus was slightly but significantly lower at $20^{\circ} \mathrm{C}$ and $30^{\circ} \mathrm{C}$ in both hosts, but averaged over $85 \%$ at the three intermediate temperatures. The sex ratio
Table 3. Percentages of survival from egg to adult emergence of $T$. triptus progeny reared on eggs of $P$. hybneri and $E$. guttiger at various constant temperatures

\begin{tabular}{ccc}
\hline \multirow{2}{*}{$\begin{array}{c}\text { Temperature } \\
\left({ }^{\circ} \mathrm{C}\right)\end{array}$} & \multicolumn{2}{c}{$\%$ survival of progeny ${ }^{\mathrm{a}}$} \\
\cline { 2 - 3 } & P. hybneri & E. guttiger \\
\hline 20.0 & $82.1 \mathrm{a}$ & $81.1 \mathrm{a}$ \\
22.5 & $88.5 \mathrm{~b}$ & $86.3 \mathrm{~b}$ \\
25.0 & $89.7 \mathrm{~b}$ & $87.7 \mathrm{~b}$ \\
27.5 & $91.5 \mathrm{~b}$ & $89.3 \mathrm{~b}$ \\
30.0 & $78.8 \mathrm{a}$ & $79.0 \mathrm{a}$ \\
\hline
\end{tabular}

a Percentages followed by different letters in the same column are significantly $(p<0.05)$ different by TukeY's test after ANOVA using arcsine-transformed data.

and head width of emerged parasitoids did not differ significantly ( $p>0.05$, by Tukey's test) with temperature or host species (Table 4). These results show that T. triptus develops normally between $20^{\circ} \mathrm{C}$ and $30^{\circ} \mathrm{C}$ 
Table 4. Sex ratios of T. triptus and head width of males when reared on egg masses of $P$. hybneri and E. guttiger at various constant temperatures

\begin{tabular}{cccccc}
\hline \multirow{2}{*}{ Temperature $\left({ }^{\circ} \mathrm{C}\right)$} & \multicolumn{2}{c}{ Sex ratio $(\% \text { males })^{\mathrm{a}}$} & & \multicolumn{2}{c}{ Head width $(\mathrm{mm})^{\mathrm{b}}$} \\
\cline { 2 - 3 } & P. hybner & E. guttiger & & P. hybner & E. guttiger \\
\hline 20.0 & 10.1 & 8.8 & 0.425 & 0.424 \\
22.5 & 9.0 & 8.2 & 0.423 & 0.425 \\
25.0 & 8.6 & 8.4 & 0.424 & 0.424 \\
27.5 & 7.6 & 8.4 & 0.423 & 0.422 \\
30.0 & 9.5 & 8.7 & 0.423 & 0.423 \\
\hline
\end{tabular}

a Means are not significantly $(p>0.05)$ different by TUKEY's test after ANOVA using arcsine-transformed data.

${ }^{b}$ For each host species at each temperature, head width of 20 males was measured. Each male was randomly sampled from parasitoid progeny of each of the 20 tested females. Means are not significantly $(p>0.05)$ different by TukeY's test after ANOVA.

in both hosts. The average temperatures recorded in Fukuoka city between 1983-1992 (10-days averages) range from a maximum of $28.6^{\circ} \mathrm{C}$ in late July to a minimum of $20.5^{\circ} \mathrm{C}$ in early October, all within the normal range of development of $T$. triptus.

The full range of temperatures for normal development of T. triptus is not known since we did not investigate the survival and development of this parasitoid below $20^{\circ} \mathrm{C}$ and above $30^{\circ} \mathrm{C}$. Studies on other scelionid species parasitic on pentatomid eggs (YEARGAN, 1983; OrR et al., 1985) demonstrated that the ranges of temperatures for normal development of Trissolcus euschistis (ASHMEAD) and Telenomus chloropus Thomson were $21-27^{\circ} \mathrm{C}$ and $24-30^{\circ} \mathrm{C}$, respectively, but that the range of Trissolcus basalis (WOLLASTON) was 18$33^{\circ} \mathrm{C}$. Although the survival rates of $T r$. euschistis were underestimated because the rates were based on total number of parasitoids which developed to adult stage inside host eggs (YEARGAN, 1983), some temperatures below $20^{\circ} \mathrm{C}$ and above $30^{\circ} \mathrm{C}$ should be tested to de- termine more exact range of temperature for normal development of T. triptus.

\section{ACKNOWLEDGEMENTS}

We thank Dr. W. A. JonEs for reading the manuscript. We also thank Dr. N. F. JoHnson for identifying the parasitoid.

\section{REFERENCES}

Higuchi, H. (1993) Appl. Entomol. Zool. 27: 363369.

Hirashima, Y. (1977) Bull. Inst. Trop. Agric. Kyushu Univ. 2: 104-115.

Kobayashi, T. (1972) JARQ 6: 212-218.

ORR, D.B., D.J. BOeThel and W.A. Jones (1985) Ann. Entomol. Soc, Am. 78: 615-619.

Thkasu, K. and Y. Hirose (1985) Proc. Assoc. Pl. Prot. Kyushu 31: 127-131.

Yeargan, K.V. (1983) Ann. Entomol. Soc. Am. 76: 757-760. 